\title{
Environmental pollution
}

\author{
Eman Abdelhady \\ Menofyia Univesity, Egypt
}

Correspondence: Eman Abdelhady, Menofyia Univesity, Egypt, Tel 0I00378480I, Email mnmn7733@yahoo.com

Received: April 04, 20I8 | Published: April I0, 2018

Copyright@ 2018 Abdelhady. This is an open access article distributed under the terms of the Creative Commons Attribution License, which permits unrestricted use, distribution, and reproduction in any medium, provided the original author and source are credited.

\section{Editorial}

Geographical scope of pollution

It refers to the areas to which the pollution extends . Pollution is divided according to its geographical extension : Local and farreaching.

\section{Local pollution}

It is intended pollution that do not exceed its territorial space and the place of its origin. The impact is limited in certain area or a particular territory or area (Nes Without that extend outside this framework. This may be the source of pollution, pollution from factories, mines and erected by the same human rights and may be due to an act of nature when they arise volcanoes potent storms and injure a component of the local environment and the Harm, Without this impact neighboring environment follow its or other continent.

\section{Long-range pollution}

Known as the Organization for Economic Cooperation and Development of this pollution as "any deliberate pollution, originating from or organic origin, subject or is present in whole or in part, in an area under the national jurisdiction of a State, and its effects, in an area under the national jurisdiction of another State." Approaching this definition, the definition by the 1979 Geneva Convention on Longrange pollution, where pollution is known as "the natural source is wholly or in part, in an area under the national jurisdiction of a State, which is the harmful effects in the area under the national jurisdiction of another State, and that it is generally possible to distinguish between the contribution of the individual or group sources emission sources." Thus we can confirm, the most important thing that distinguishes the long-range pollution, that it moves from the state which occurs in the territory of another State, without the possibility of blocked or prevented from crossing to the affected State. The first image: crossborder pollution is one way, which is to find the source of pollution in the state, and produces its effects in another State or more. The second picture: pollution across the border with directions, or mutuality, marine pollution, find its source in the state of, and produces its effects in another State, there are in this state of pollution sources to produce their effects in the first State. Cross-border pollution that can occur on the aquatic environment. The environment bicycles it raises many problems both at the level of domestic law, or on the level of international law. Since the environment was a humanitarian one, and the commitment to protect the integral part, been the international conventions on the development of a legal regime to combat this type of pollution, including requiring the commitment to cooperation between States, as air environment, for example, is one of the common natural resources, and therefore is not fit to be the subject of private property by one of whether a State or individual. And that every State has the duty to take into account respect for standards or acceptable levels applied internationally, concerning the protection of the air, this is without prejudice to other measures to improve environmental quality.

\section{The polluted environment}

The following is a list of the most important forms of pollution with organic pollutants for each form of them:

\section{Air pollution}

The harmful chemicals and particulates in the atmosphere lead to air pollution. Common gaseous air pollutants, including carbon monoxide, sulfur dioxide, chlorofluorocarbons (Cfcs) nitrogen oxide produced by industry absorb car engines.

The industrial progress also led to tremendous pressure on many natural resources, the environment is no longer capable of renewing its resources consumption, waste resulting from the various human activities, smoke rising from the car exhausts and CHIMNEYS factories and power stations to add to some of the defects or fumes heavy metals emission led to air pollution, where these fumes remain suspended in the air for several days, this is what we call foggy smog, and the serious effects do not appear on the rights directly, but it could lead in the long term to dementia dementia disorder manifests itself attention, memory, and illusions, including leads to mental depression, which affects the respiratory system. That air pollution here cause in the wintry days what we call acid precipitation is a phenomenon which drew attention to it after that caused damage to agriculture, animal husbandry and fishery many wealth, according to the nature of the food chain, according to the movement of air pollution moves from one place to another, and geographical environment to another, as the PLANKTON melt mobile water vapor in the air and come back again to the soil, if we add to this the dumping of waste including waste disposal of human excreta, industrial waste and outputs high toxic chemicals in waterways, we become aware of the magnitude of 
the tragedy in the environment due to human frailty and the harmful effects attributable to his actions despite his growing consciousness and teach him.

\section{Soil pollution}

soil pollution is defined by some as "the corruption that plagues the soil wegger of natural attributes and characteristics, chemical or biotechnology, or alter the installed on it negatively affect - directly or indirectly - on living on the surface of human beings and animals, and plants." (soil contamination of the chemicals that spilled or leaked underground among the most important causes of contaminated soil is the HYDROCARBONS and heavy metals. There are many causes and sources of lead to the pollution of the soil, the contaminated soil as a result of the fall of acid rain, or as a result of the fall of the fallout from nuclear explosions caused by the rights of the planet Earth. The soil may also be polluted by agricultural pesticides leading to inflict serious damage on the soil specifications, which would have a negative impact on the food, which was the subject of human rights.

\section{Water pollution}

Contamination water is damage or spoil the quality of the water by changing the chemical fezex 1 attributes harmful becomes unusable and dangerous to the environment and living organisms.

There is no real separation between air pollution and water because the polluted air affect a lot in the areas of water

Fresh water is the lifeblood of most of the organisms, and freshwater resources $(3 \%)$ of the total volume of the waters of the earth, this percentage, although modest, it faces many problems is the steady deterioration in the quality and relevance to meet the intended uses, because of pollution from various major activities, and the coup d'état the enormous industrial, population explosion and other reasons that led to the pollution of the water and make it unsuitable for use required for life. 